\title{
Level of stress among spouses of Alcoholic men.
}

\author{
Savita, Sulekha, Swati Dadwal, Uma Bhatt, Varsha Bijalwan ${ }^{1}$ Dipti Sorte ${ }^{2}$ \\ ${ }^{I}(R N$, Himalayan Institute Hospital Trust, Uttarakhand) \\ ${ }^{2}$ (Associate Professor, Himalayan College of Nursing, SRHU, Uttarakhand)
}

\begin{abstract}
:
Introduction: Alcohol is a family disease it drawn effects on the person who is drinker and whole the family but the mostly affected person is the spouses of the drinker. Alcoholism affect emotionally, physically, socially and psychologically. Spouses feel difficult to manage her married life and feel stress. The objectives of the study is To assess the stress level among spouses of alcoholic men and To find association between stress level and selected socio demographic variables. The study was reviewed under the heading like literature related to Personality of wives of alcoholics, literature related to Stressful situations in wives of alcoholic, literature related to Familial and marital interactions and children of alcoholics and literature related to wives responses to Alcoholism
\end{abstract}

Methodology: the research approach used was quantitative non experimental descriptive survey, study setting was conducted in community Ranipokhri Dehradun, population was the spouses of alcoholic dependents, purposive sampling technique was used to choose the participant. Tool used was modified in four point Likert scale to assess the stress level among spouses of alcoholic men. Pilot study was conducted from $10 \%$ of entire population. Data collection process was done in the period of two days, whole research process was started with identifying subject participant permission was obtained from principal, purpose was explained to subject participants and consent were taken and administrated tools to 50 subject participant for data collection then proceeded for data analysis. Overall data was organized with the help of table and graphical presentation.

Result:The Demographic variables of fifty spouses were administrate the tool section one \& two Where in section one the majority 38(66\%) participants aged between 21 - 40yrs and less majority 2(4\%) were found in $51-60 y r s$. and maximum duration of marriage 24(48\%) was between 0 to 10 yrs. And less is 1(2\%). Maximum $32(64 \%)$ husband was found to be occasional drinker and all 50(100\%). The families were belongs to Hindu Religion. Maximum education of Husband was High school 17(34\%) and less is post graduate 1(2\%). Whereas maximum education of wives was primary school 12(24\%) and less was found 8(16\%). Majority participants 48(96\%) had Arrange marriage and less was (2) 4\% was Love marriage, whereas majority participants were living in nuclear family that is 30(60\%) and less participants 20(40\%) was in joint family Whereas, Section two findings were analyzed as per objectives of the study

Conclusion: The Demographic variables like Age of Wives where Nineteen participants found increase in the stress level between twenty one to forty yrs. of age. Duration Of Marriage where, ten participants found increase the stress level in the spouse whose marriage duration was between twenty one to thirty yrs. Drinking habit of Husband where eighteen participants stress level was increased whose husband was found to be habitual drinker. All the fifty participant was Hindu who has increase in stress level. Education of Husband where 10 husbands of spouses was had primary education and their spouses were has increased stress level, Education of Wives where eight participant was found to high in stress level whose education was up to high school level, Type of marriage where forty eight spouses was had arrange marriage whose stress level was high, and lastly the type of family where thirty participants was from nuclear family whose stress level was high. Study was implicated through the area of nursing education, nursing practice, nursing administration, nursing research.

Keywords: Stress, Alcoholic men, Spouses.

\section{Introduction}

Alcohol is a family disease it drawn effects on the person who is drinker and whole the family but the mostly affected person is the spouses of the drinker. Alcoholism affect emotionally, physically, socially and psychologically. Spouses feel difficult to manage her married life and feel stress. The objectives of the study is To assess the stress level among spouses of alcoholic men and To find association between stress level and selected socio demographic variables. The study was reviewed under the heading like literature related to Personality of wives of alcoholics, literature related to Stressful situations in wives of alcoholic, literature related to Familial and marital interactions and children of alcoholics and literature related to wives responses to Alcoholism 


\section{Objective}

2.1. To assess the stress level among spouses of alcoholic men.

2.2. To compare the stress level of alcoholic spouses based on their socio-demographic variables.

\section{Hypotheses}

3.1. $\mathrm{H}_{1}$ : The spouses of alcoholics will experience stress.

\section{Review Of Literature:}

The Literature is reviewed under the following heading:

4.1. Review of literature related to Personality of wives of alcoholics.

4.2. Review of literature related to Stressful situations in wives of alcoholics.

4.3. Review of literature related to Familial and marital interactions and children of alcoholics.

4.4. Review of literature related to wives responses to Alcoholism.

\section{Limitations:}

5.1. All the wives were not involved in the study.

5.2. Study is limited to selected area of Dehradun.

5.3. Study is limited to certain period of time.

\section{Variables:}

6.1. Dependent Variable: Stress level of spouses.

6.2. Independent Variable: Alcoholic Men.

6.3. Background Variable: Age of couple, Duration of a marriage, Drinking habit, Religion, Education, Income, occupation, Type of marriage, No. of children.

\section{Research Methodology}

Research Approach: Quantitative non experimental approach as it was considered to be the most suitable for the study.

Research Design: The Research Design used for this study was exploratory descriptive design.

\section{Sample and Sampling Technique:}

Sample size: The sample size was 50 spouses of alcoholic men.

Sampling technique: In the study sample was spouses of alcoholic men and were selected by purposive sampling technique

\section{Sampling criteria:}

\section{Inclusion criteria-}

- Who is willing to participate in the study?

- Wives age between 18 to 60 .

- Married couple living with alcoholic partner with current alcohol problem

\section{Exclusive criteria-}

- Who are suffering from chronic physical and psychiatric problem?

- $\quad$ Severe domestic violence.

- Own alcoholic/drug problem

Setting: The Study was conducted in community area of Ranipokhri, Dehradun.

Data collection method: Before data collection purpose of the study was explained to the participant and informed consent was obtained then tools were administered to participants and confidentially were maintained with the help of purposive sampling 30 wives were selected and administrate the tool.

Data collection procedure: Four point Likert's scale includes opinion of the wives in terms of never, sometime, often and always was used. Total 30 items were included in the subject of husbands behavior which generate stress to their wives.

Validity and reliability: Tool is sent to different experts of the field for reliability and it was found to be a consistent.

\section{Results:}

The Demographic variables of fifty spouses were administrate the tool section one \& two Where in section one the majority $38(66 \%)$ participants aged between $21-40 \mathrm{yrs}$ and less majority $2(4 \%)$ were found in $51-60 \mathrm{yrs}$. and maximum duration of marriage $24(48 \%)$ was between 0 to $10 \mathrm{yrs}$. And less is $1(2 \%)$. Maximum 
$32(64 \%)$ husband was found to be occasional drinker and all $50(100 \%)$. The families were belongs to Hindu Religion. Maximum education of Husband was High school 17(34\%) and less is post graduate 1(2\%). Whereas maximum education of wives was primary school $12(24 \%)$ and less was found $8(16 \%)$. Majority participants $48(96 \%)$ had Arrange marriage and less was (2) $4 \%$ was Love marriage, whereas majority participants were living in nuclear family that is $30(60 \%)$ and less participants $20(40 \%)$ was in joint family Whereas, Section two findings were analyzed as per objectives of the study

\section{Summary:}

In a short the wives of alcoholic men is found under stress but the level of stress is differs from age, duration of marriage, drinking habits, religion, education, and type of family. We have seen the literature shows that Personality of wives of alcoholics, Stressful situations in wives of alcoholics, Familial and marital interactions and children of alcoholics and wives responses to Alcoholism through which it is proved that family, personality get effect of wives whose husband is alcoholic. The data is analyzed through descriptive statistics and the entire project is communicated.

\section{Conclusion}

The primary aim of this study was to assess the stress level among spouses of alcoholic men through four point Likert's scale regarding alcoholism and its effect in alcoholic husband's wives by house to house survey approach. In this study purposive sampling used. This study shows that the levels of stress among wives are more in the women whose husband are victim of alcohol addiction.

\section{Nursing Implications}

The Nursing implication of the study is given as follows:

\subsection{Nursing education}

Nursing curriculum equip the students with the essential knowledge, skills and attitude to fulfill their duties and responsibilities during the upcoming professional life. Assess stress level among wives of alcoholic men through curriculum activities in community setting.

\subsection{Nursing practice}

The expanded role of the professional or student nurse emphasizes those activities which assess the stress level among alcoholic men's wives in community.

\subsection{Nursing Administration}

Nursing has become a complex and highly varied practice descriptive with the rapid growing, well developed and well documented scientific and humanistic information based. Nurse administrators are the back bone to provide facilities to relieve their stress. There should be a provision for nurse to developed time for giving health education and conducting educational programmed in community setups. A hospital policy should be adopted to provide health education or written information to the alcoholic husband wife in community.

\subsection{Nursing research}

Finding of the study will acts as a catalyst to carry out more expensive research on a large population sampling in different areas of community. Therefore there is a need to conducted further studies in this area.

\section{Recommendations:}

12.1. The study can be done to assess the coping level of wives whose husbands are alcoholic.

12.2. Similar study can be carried out in urban level.

12.3. Similar study can be carried out for children whose father is habitual drinker.

12.4. The study can be done on husbands whose wives are alcoholic.

12.5. The Qualitative study can be carried out to assess the alcoholic effect on relationship of couple.

12.6. Exploratory study to assess the reasons of alcoholism in community.

\section{Reference}

[1]. "Diagnostic Criteria for Alcohol Abuse and Dependence - Alcohol Alert No. 30-1995". Archived from the original on 27 March 2010. Retrieved 17 April 2010.

[2]. Caan, Woody; Belleroche, Jackie de, eds. (11 April 2002). Drink, Drugs and Dependence: From Science to Clinical Practice (1st ed.). Routledge. pp. 19-20. ISBN 978-0-415-27891-1.

[3]. WHO. "Lexicon of alcohol and drug terms published by the World Health Organization". World Health Organisation.

[4]. Tracy, Sarah J. (25 May 2005). Alcoholism in America: from reconstruction to prohibition. Baltimore: Johns Hopkins University Press. pp. 31-52. ISBN 978-0-8018-8119-0.

[5]. Ms Leanne Riley (31 January 2003). "WHO to meet beverage company representatives to discuss health-related alcohol issues". World Health Organisation. http://www.ias.org.uk/resources/papers/europe/phproject/bingedrinking-report.pdf

[6]. "Global Status Report on Alcohol 2004" (PDF). World Health Organization. Archived from the original on 30 December 2006. Retrieved 3 January 2007.

[7]. WHO. "Lexicon of alcohol and drug terms published by the World Health Organization". World Health Organisation. 
[8]. Tracy, Sarah J. (25 May 2005). Alcoholism in America: from reconstruction to prohibition. Baltimore: Johns Hopkins University Press. pp. 31-52. ISBN 978-0-8018-8119-0.

[9]. Dr Gro Harlem Brundtland (19 February 2001). "WHO European Ministerial Conference on Young People and Alcohol". World Health Organisation.

[10]. Ms Leanne Riley (31 January 2003). "WHO to meet beverage company representatives to discuss health-related alcohol issues". World Health Organisation

[11]. Dr.Nagarajaiah,level of coping among the wife of alcoholic dependents, journals of NRSI, page no. 30 to 35 , vol.4no,1april-may 2011

[12]. http://www.iapsmupuk.org/journal/index.php/IJCH/article/view/442 